\title{
Comparison of growth characteristics of anaerobic fungi isolated from ruminant and non-ruminant herbivores during cultivation in a defined medium
}

\author{
Marcel J. Teunissen, ${ }^{1 *}$ Hudb J. M. Op den Camp, ${ }^{1}$ Colin G. Orpin, ${ }^{2,3}$ \\ Jos H. J. Huis IN 'T VELD ${ }^{4}$ AND GODFRIEd D. Vogels ${ }^{1}$
}

${ }^{1}$ Department of Microbiology, Faculty of Science, University of Nijmegen, Toernooiveld, NL-6525 ED Nijmegen,
The Netherlands
${ }^{2}$ CSIRO Division of Tropical Crops and Pastures, 306 Carmody Road, St Lucia, Queensland 4067, Australia
${ }^{3}$ Institute of Medical Biology and Department of Arctic Biology, University of Tromsø, 9001 Tromsø, Norway
${ }^{4}$ Department of Microbiology, TNO-CIVO Food Analysis Institute, Utrechtseweg 47, NL-3704 HE Zeist,
The Netherlands

(Received 19 November 1990; revised 22 February 1991; accepted 15 March 1991)

\begin{abstract}
Anaerobic fungi were isolated from rumen fluid of a domestic sheep (Ovis aries; a ruminant) and from faeces of five non-ruminants: African elephant (Loxodonta africana), black rhinoceros (Diceros bicornis), Indian rhinoceros (Rhinoceros unicornis), Indian elephant (Elephas maximus) and mara (Dolichotis patagonum). The anaerobic fungus isolated from the sheep was a Neocallimastix species and the isolates from non-ruminants were all species similar to Piromyces spp. A defined medium is described which supported growth of all the isolates, and was used to examine growth characteristics of the different strains. For each fungus the lipid phosphate content was determined after growth on cellobiose and the resulting values were used to estimate fungal biomass after growth on solid substrates. The ability of isolates from ruminants and non-ruminants to digest both wheat straw and cellulose was comparable. More than $90 \%$ and $60 \%$, respectively, of filter paper cellulose and wheat straw were digested by most strains within 60-78 h. Growth of two fungi, isolated from rumen fluid of a sheep (Neocallimastix strain N1) and from faeces of an Indian rhinoceros (Piromyces strain R1), on cellobiose was studied in detail. Fungal growth yields on cellobiose were $64.1 \mathrm{~g}$ (mol substrate) ${ }^{-1}$ for $\mathrm{N1}$ and $34.2 \mathrm{~g} \mathrm{~mol}^{-1}$ for R1. The major fermentation products of both strains were formate, lactate, acetate, ethanol and hydrogen.
\end{abstract}

\section{Introduction}

Anaerobic fungi inhabit defined regions of the alimentary tract of herbivorous mammals. Orpin $(1975,1976$, 1977) first recognized that many of the flagellates present in ovine rumen fluid were zoospores of anaerobic fungi. Since then anaerobic fungi have been isolated both from ruminants, e.g. sheep, cattle, macropod marsupials (Bauchop, 1979; Orpin \& Joblin, 1988; Barr, 1988), and from faeces of non-ruminants, e.g. horse (Orpin, 1981), elephant, zebra (Milne et al., 1989).

On morphological grounds anaerobic fungi were classified in the Class Chytridiomycetes (Heath et al., 1983), but on the basis of the ultrastructural characteristics of the zoospores, they were assigned to the new family Neocallimasticaceae (Barr, 1988). Gold et al.

Abbreviation: DM, dry matter.
(1988) suggested a subdivision of this family into the three genera containing monocentric species - Neocallimastix, Piromyces (previously Piromonas) and Caecomyces (previously Sphaeromonas) - which at that time were the only legitimately described genera of anaerobic fungi. Subsequently polycentric species have been described, e.g. Orpinomyces bovis (Barr et al., 1989) and Neocallimastix joyonni (Breton et al., 1989). Up to now, six anaerobic fungi isolated from foregut fermenters (sheep, cow) have been classified, namely: Neocallimastix patriciarum (Orpin \& Munn, 1986), Neocallimastix frontalis (Heath et al., 1983), Neocallimastix joyonni (Breton et al., 1989), Piromyces communis (Orpin, 1977), Caecomyces communis (Orpin, 1976, 1988) and Orpinomyces bovis (Barr et al., 1989). The latter however does not conform to the proposed generic description. Only one fungal species from a non-ruminant (horse) has been named, Caecomyces equi (Gold et al., 1988). 
Zoospores of anaerobic fungi invade freshly ingested plant tissue (Orpin \& Bountiff, 1978), and the vegetative stadia closely associate with, and grow at the expense of, plant particles (Lowe et al., 1987b). The anaerobic fungi produce a range of cell-bound and extracellular polysaccharide-degrading enzymes which participate in the digestion of food particles (Lowe et al., 1987b; Williams \& Orpin, 1987). The role of anaerobic fungi in the alimentary tract is not yet clear. The rumen fungi are the initial colonizers of plant fragments (Bauchop, 1979) and pure cultures in vitro digest up to $43 \%$ of wheat straw on a dry matter basis (Lowe et al., 1987b). Little is known about the digestion of wheat straw and cellulose by anaerobic fungi inhabiting non-ruminant herbivores.

This study was performed to compare the growth characteristics of anaerobic fungi isolated from ruminant and non-ruminant herbivores. A defined medium was developed to study the digestion of filter paper cellulose and wheat straw by newly isolated anaerobic fungi from non-ruminants and other already described species isolated from a ruminant, the sheep.

\section{Methods}

Source of organisms. Rumen fluid was collected from a fistulated sheep, fed on a grass hay-concentrate diet, at the farm of the University of Nijmegen. Fresh faeces from the non-ruminant animals were gathered into plastic bags from the floor of the mammal enclosure at London Zoo (Regent's Park, London, UK) and the Zoo at Whipsnade (UK). Neocallimastix patriciarum (N2), Piromyces communis (P1), Piromyces sp. (P2), Caecomyces communis (S1) (Orpin, 1975, 1976, 1977) isolated from the rumen of sheep and a Piromyces sp. (P3) isolated from faeces of a horse (Orpin, 1981) were obtained from the fungal collection of the AFRC Institute of Animal Physiology and Genetics Research, Babraham, Cambridge, UK.

Culture conditions. Two media were used to culture anaerobic fungi: complex medium $\mathrm{M} 1$, which contained rumen fluid, and a defined medium M2. Salt solutions $A$ and $B$ were used in medium preparation. Solution A contained $\left(\mathrm{g} \mathrm{l}^{-1}\right) \mathrm{KH}_{2} \mathrm{PO}_{4}, 3 \cdot 0 ;\left(\mathrm{NH}_{4}\right)_{2} \mathrm{SO}_{4}, 3.0 ; \mathrm{NaCl}, 6 \cdot 0$; $\mathrm{MgSO}_{4}, 0 \cdot 6 ; \mathrm{CaCl}_{2}, 0 \cdot 6$; solution B contained $\mathrm{K}_{2} \mathrm{HPO}_{4}, 3 \mathrm{~g} \mathrm{l}^{-1}$.

Complex medium M1 was modified from Kempet al. (1984) and had the following composition: solution A, $150 \mathrm{ml}$; solution B, $150 \mathrm{ml}$; centrifuged rumen fluid (Orpin; 1977), $200 \mathrm{ml}$; Bactocasitone (Difco), $10 \mathrm{~g}$; yeast extract (Oxoid), $2.5 \mathrm{~g}$; $\mathrm{NaHCO}_{3}, 6 \mathrm{~g}$; L-cysteine. $\mathrm{HCl}, 1 \mathrm{~g}$; fructose, $2 \mathrm{~g}$; xylose, $2 \mathrm{~g}$; cellobiose, $2 \mathrm{~g}$; resazurin solution $(0.1 \%$, w/v), $1 \mathrm{ml}$; agar (for solid medium), $8 \mathrm{~g}$; deionized water to $900 \mathrm{ml}$. The medium was equilibrated with oxygen-free $\mathrm{CO}_{2}$ and dispensed in $9.0 \mathrm{ml}$ volumes into $16.5 \mathrm{ml}$ screw-top Hungate culture tubes (Bellco Glass). After sealing, the tubes were evacuated and gassed with $\mathrm{N}_{2} / \mathrm{CO}_{2}(80: 20, \mathrm{v} / \mathrm{v})$. The medium was then autoclaved for $20 \mathrm{~min}$ at $115^{\circ} \mathrm{C}$. After cooling, $0.1 \%(\mathrm{v} / \mathrm{v})$ vitamin solution 1 was added. Vitamin solution 1 contained $\left(\mathrm{g} \mathrm{l}^{-1}\right)$ : thiamin. $\mathrm{HCl}, 0 \cdot 10$; riboflavin, $0 \cdot 20$; calcium $D$-pantothenate, $0 \cdot 60$; nicotinic acid, 1.00 ; nicotinamide, 1.00 ; folic acid, 0.05 ; cyanocobalamin, 0.20 ; biotin, 0.20 ; pyridoxine . $\mathrm{HCl}, 0.10 ; p$-aminobenzoic acid, 0.01 . In isolation procedures $0.1 \%$ $(\mathrm{v} / \mathrm{v})$ antibiotic solution was added to the medium. It contained chloramphenicol $\left(5 \mathrm{~g} \mathrm{l}^{-1}\right)$ and ampicillin $\left(10 \mathrm{~g} \mathrm{t}^{-1}\right)$.

The defined medium $M 2$ contained: solution $A, 150 \mathrm{ml}$; solution $B$, $150 \mathrm{ml}$; cellobiose, $5 \mathrm{~g}$; $\mathrm{NaHCO}_{3}, 6$; L-cysteine. $\mathrm{HCl}, 1$; trace elements solution, $10 \mathrm{ml}$; haemin solution, $10 \mathrm{ml}$; resazurin solution $(0.1 \%$, w/v),
$1 \mathrm{ml}$; demineralized water to $950 \mathrm{ml}$. The medium was dispensed in $19.0 \mathrm{ml}$ volumes in $50 \mathrm{ml}$ serum bottles and sealed with butyl rubber stoppers and aluminium crimp caps (D. Prins BV, Schipluiden, The Netherlands). Where specified, the cellobiose was replaced by $0.1 \mathrm{~g}$ filter paper cellulose (Whatman no. 1) or wheat straw. The composition of wheat straw was determined by the proximate method of Goering \& Van Soest (1970). It contained, on a dry matter basis, 93\% organic matter, $47 \%$ cellulose, $31 \%$ hemicellulose, and $11 \%$ lignin. After sterilization of the medium, $0 \cdot 1 \%(\mathrm{v} / \mathrm{v})$ vitamin solution 2 was added. The trace element and haemin solutions were prepared as described by Lowe et al. (1985). Vitamin solution 2 contained (mg l-1): thiamin. $\mathrm{HCl}$, 5; riboflavin, 5; calcium D-pantothenate, 5 ; nicotinic acid, 5 ; folic acid, 2 ; cyanocobalamin, 1 ; biotin, 1 ; pyridoxin. $\mathrm{HCl}, 10$; $p$ aminobenzoic acid, 5. No antibiotics were included in medium M2.

Isolation procedures. Antibiotics solution 1 was included in medium M1 during the isolation procedures until isolates were pure and free from bacteria. Especially the chloramphenicol was shown to be effective in eradication of methanogens and mycoplasmas which can contaminate anaerobic fungal isolates (Kudo et al., 1990).

The rumen fungi were isolated from serial dilutions $\left(10^{-1}-10^{-5}\right)$ of strained rumen fluid in M1 broth without substrate. Subsequently, $1.0 \mathrm{ml}$ of each dilution was inoculated in Hungate tubes with molten M1 agar at $44^{\circ} \mathrm{C}$. After $3 \mathrm{~d}$ incubation at $39^{\circ} \mathrm{C}$, individual colonies from dilution tubes with fewer than 20 colonies were transferred with a sterile Pasteur pipette to Ml broth. After $2 \mathrm{~d}$ the culture fluid was again diluted and the procedure was repeated until the isolates were pure and free of bacteria.

Anaerobic fungi from non-ruminants were isolated from collected faecal samples by cultivation in Ml broth in Hungate tubes. The fungi were isolated from the culture fluid after $3 \mathrm{~d}$ incubation at $39^{\circ} \mathrm{C}$ using the procedures described for isolations from strained rumen fluid.

Culture conditions. Stock cultures were maintained on $0 \cdot 1 \mathrm{~g}$ milled wheat straw in $19 \mathrm{ml}$ medium M2. Cultures were inoculated with $1 \mathrm{ml}$ of culture fluid (containing zoospores), and subcultured every 3-4 d. Stock cultures were preserved anaerobically at $-80^{\circ} \mathrm{C}$ or in liquid nitrogen in medium M2 with $5 \%(\mathrm{v} / \mathrm{v})$ dimethylsulphoxide (DMSO) as cryoprotectant. The DMSO $(0.25 \mathrm{ml})$ was added anaerobically to $5 \mathrm{ml}$ of $3 \mathrm{~d}$-old cultures of anaerobic fungi and the cultures were subsequently stored at $-80^{\circ} \mathrm{C}$. For storage over longer periods (more than 6 months) cultures were placed in liquid nitrogen after $1 \mathrm{~d}$ at $-80^{\circ} \mathrm{C}$. Frozen cultures were resuscitated by rapid thawing at $39^{\circ} \mathrm{C}$ and inoculating in fresh medium M2 with cellobiose as substrate.

Inocula $(5 \%, v / v)$ for growth experiments on cellobiose, wheat straw and cellulose were cultured for $3 \mathrm{~d}$ at $39^{\circ} \mathrm{C}$ in medium $\mathrm{M} 2$ with cellobiose as substrate. Growth of the fungi was monitored by measuring hydrogen production. After growth had stopped, triplicate cultures were harvested and fermentation products, fungal biomass and substrate utilization were determined.

Sample collection. Cultures were harvested on glass-fibre filters (grade C, Whatman), washed twice with $20 \mathrm{ml}$ deionized water, and freeze-dried overnight. The dried filters with fungus and substrate residue were stored at $-20^{\circ} \mathrm{C}$. Samples of the culture fluid (filtrate) were stored at $-20^{\circ} \mathrm{C}$ for later analysis of water-soluble sugars and fermentation products. The biomass produced by growth on soluble sugars was determined from dry weight measurements. Growth of the fungus on wheat straw and filter paper cellulose was estimated from the lipid phosphate content. Phosphate release by perchloric acid digestion of the phospholipid extract was correlated with the fungal dry matter (DM) (White et al., 1979). The lipid phosphate content of wheat straw cultures was corrected for the background lipid phosphate level of wheat straw $\left[0.034 \mathrm{mg}\right.$ phosphate $\left.(\mathrm{g} \mathrm{DM})^{-1}\right]$. The correlation of biomass and lipid phosphate content was determined for each fungus after growth on cellobiose in medium M2. 
Determination of digestion of wheat straw and cellulose. The extent of digestion of cellulose and wheat straw was calculated by subtracting the estimated fungal biomass from the total mass of the fraction collected after growth. For wheat straw, values were also corrected for dry weight losses due to non-microbial solubilization of the material which occurred during preparation and incubation of the medium $(15 \cdot 1 \% \pm 0.5 \%)$.

Analytical procedures. Formic acid was determined by the colorimetric method of Sleat \& Mah (1984). Other fermentation products were determined by GLC using the method of Teunissen et al. (1989) with a Hewlett Packard HP 5890A gas chromatograph. The column was packed with GP $10 \%$-SP 1200 on Chromosorb WAW $/ 1 \% \mathrm{H}_{3} \mathrm{PO}_{4}$ (Supelco). Hydrogen in $0.5 \mathrm{ml}$ of head-space gas samples was quantified with a Hewlett Packard HP 5890A gas chromatograph fitted with a thermal conductivity detector and a column packed with 80-100 mesh Porapack Q (Supelco). Ethane was used as internal standard and hydrogen as external standard.

Soluble sugars were quantified by enzymic methods. Glucose was determined using glucose oxidase and peroxidase (Bergmeyer \& Bernt, 1974). The same assay was used to determine cellobiose after enzymic hydrolysis with $\beta$-D-glucoside glucohydrolase (EC 3.2 .1 .21) (Russell \& Baldwin, 1978).

\section{Results}

\section{Isolation of anaerobic fungi from rumen fluid and faeces}

Anaerobic fungi could be isolated, using medium M1, from faeces of six of the ten species of animal surveyed (Table 1). The fungi could also be isolated from faeces stored for up to $8 \mathrm{~h}$ in a plastic bag at room temperature (longer storage periods were not tested). All the isolates grew in medium M1 in which the carbohydrates were replaced by wheat straw as substrate. One fungus was isolated from the rumen fluid of a sheep; this species formed monocentric sporangia borne on an extensive network of branched rhizoids; the zoospores possessed up to 20 flagella. All fungi isolated from faeces of the non-ruminants produced zoospores with not more than four flagella (generally one or two), and monocentric sporangia borne on an extensively branched rhizoid.

\section{Growth of anaerobic fungi on cellobiose in the complex medium M1 and the defined medium M2}

The anaerobic fungi were isolated and cultivated in complex medium M1. A defined medium in which all isolated fungi grew well was obtained by omitting the yeast extract, Bactocasitone and rumen fluid from medium M1. Although haemin was necessary for optimal growth, vitamin solution 2, which contained 100-1000 times less vitamins than vitamin solution 1 , ensured good growth of the fungi. All the newly isolated strains grew in medium M2 with cellobiose or wheat straw as substrate. Most of the strains from the fungal collection of the AFRC Institute could be grown in this medium. However, Piromyces strain P3 and Caecomyces communis strain S1 failed to grow in medium M2.

\section{Growth on cellobiose in defined medium M2 and determination of the lipid phosphate content of the different strains}

The different strains were cultured on cellobiose in medium M2 and growth was monitored by measurement of $\mathrm{H}_{2}$ production. After $\mathrm{H}_{2}$ production ceased the fungi were harvested and the lipid phosphate content was determined for each strain (Table 2). At this time significant autolysis of the fungi occurred (see Fig. 1). Piromyces strains E1 (isolated from African elephant) and R3 and R4 (isolated from an Indian rhinoceros) grew slowly and the amount of fungal biomass formed was relatively low. The Neocallimastix strain isolated from the sheep rumen $(\mathrm{N} 1)$ and the AFRC sheep rumen isolates (Neocallimastix strain N2 and Piromyces strains $\mathrm{P} 1$ and $\mathrm{P} 2$ ) produced more hydrogen and yielded more fungal DM than the isolates from the hindgut fermenters. The lipid phosphate content of each fungus was calculated and varied between 1.97 and $3.51 \mathrm{mg}$ lipid phosphate per $\mathrm{g}$ fungal $\mathrm{DM}$. The lipid phosphate content

\section{Table 1. Isolation of anaerobic fungi from the faeces and rumen fluid of herbivorous mammals}

Anaerobic fungi were not isolated from faecal samples of the following animals: African wood elephant (Loxodonta cyclotis), white rhinoceros (Ceratotherium simum), hippopotamus (Hippopotamus amphibius) and pygmy hippopotamus (Choeropsis liberiensis).

\begin{tabular}{|c|c|c|c|c|}
\hline Animal & $\begin{array}{l}\text { Place of } \\
\text { isolation }\end{array}$ & Major diet & Code & Fungal type \\
\hline African elephant (Loxodonta africana) & Whipsnade & Clover hay, concentrate & El & Piromyces \\
\hline Indian elephant (Elephas maximus) & London Zoo & Clover hay, concentrate, vegetables & E2 & Piromyces \\
\hline Indian elephant (Elephas maximus) & Whipsnade & Clover hay, concentrate, vegetables & E3 & Piromyces \\
\hline Black rhinoceros (Diceros bicornis) & London Zoo & Clover hay, concentrate & $\mathbf{R} \mathbf{1}$ & Piromyces \\
\hline Black rhinoceros (Diceros bicornis) & Whipsnade & Clover hay, concentrate, vegetables & $\mathbf{R} 2$ & Piromyces \\
\hline Indian rhinoceros (Rhinoceros unicornis)* & Whipsnade & Clover hay, concentrate, vegetable & R3/R4 & Piromyces \\
\hline Mara (Dolichotis patagonum) & Whipsnade & Grass, hay & M1 & Piromyces \\
\hline Sheept (Ovis aries) & Nijmegen & Grass, hay & Nl & Neocallimastix \\
\hline
\end{tabular}

\footnotetext{
* Isolated from faeces from one animal.

$\dagger$ A ruminant; all other animals are non-ruminants.
} 
Table 2. Hydrogen production, biomass, and lipid phosphate content of different strains of anaerobic fungi after growth in defined medium $M 2$ with cellobiose as substrate

Each experimental value represents the mean $\pm \operatorname{SD}(n=3)$.

\begin{tabular}{|c|c|c|c|c|c|}
\hline Strain & $\begin{array}{l}\text { Incubation } \\
\text { time } \\
\text { (h) }\end{array}$ & $\begin{array}{l}\text { Hydrogen } \\
\text { production } \\
\left(\mathrm{mmol} \mathrm{l}^{-1}\right) \dagger\end{array}$ & $\begin{array}{c}\text { Fungal } \\
\text { DM } \\
\left(\mathrm{g} \mathrm{l}^{-1}\right)\end{array}$ & $\begin{array}{c}\text { Lipid } \\
\text { phosphate } \\
\left(\mathrm{mg} \mathrm{l}^{-1}\right)\end{array}$ & $\begin{array}{c}\text { Lipid phosphate } \\
\text { content } \\
{\left[\mathrm{mg} \mathrm{PO}_{4}^{3-}(\mathrm{g} \mathrm{DM})^{-1}\right]}\end{array}$ \\
\hline E1 & 92 & $7 \cdot 11 \pm 0 \cdot 80$ & $0 \cdot 24 \pm 0.02$ & $0.72 \pm 0.06$ & $2.94 \pm 0.30$ \\
\hline E2 & 120 & $5.82 \pm 0.74$ & $0.24 \pm 0.01$ & $0.70 \pm 0.02$ & $2 \cdot 92 \pm 0.14$ \\
\hline E3 & 92 & $4.98 \pm 0.42$ & $0.39 \pm 0.02$ & $1.09 \pm 0.05$ & $2.79 \pm 0.18$ \\
\hline M1 & 90 & $6.75 \pm 0.38$ & $0.33 \pm 0.02$ & $0.95 \pm 0 \cdot 10$ & $2.88 \pm 0.03$ \\
\hline N1 & 90 & $9 \cdot 11 \pm 0 \cdot 21$ & $0.57 \pm 0.00$ & $1.40 \pm 0.01$ & $2.46 \pm 0.04$ \\
\hline $\mathrm{N} 2 *$ & 92 & $9.04 \pm 0.16$ & $0.52 \pm 0.02$ & $1 \cdot 36 \pm 0 \cdot 15$ & $2.60 \pm 0.39$ \\
\hline $\mathrm{Pl}^{*}$ & 120 & $8.63 \pm 0.26$ & $0.45 \pm 0.01$ & $1.06 \pm 0.04$ & $2.32 \pm 0.06$ \\
\hline $\mathbf{P} 2^{*}$ & 90 & $8 \cdot 10 \pm 0.02$ & $0.40 \pm 0.01$ & $1.05 \pm 0.07$ & $2 \cdot 60 \pm 0 \cdot 11$ \\
\hline $\mathbf{R} 1$ & 92 & $8.11 \pm 0.03$ & $0.37 \pm 0.01$ & $0.95 \pm 0.06$ & $2.58 \pm 0.22$ \\
\hline $\mathbf{R} 2$ & 144 & $5.28 \pm 0.63$ & $0.40 \pm 0.03$ & $0.79 \pm 0.09$ & $1.97 \pm 0.26$ \\
\hline R3 & 166 & $5 \cdot 38 \pm 0.98$ & $0.26 \pm 0.05$ & $0.79 \pm 0.04$ & $3.06 \pm 0.26$ \\
\hline R4 & 148 & $5 \cdot 21 \pm 0.40$ & $0.25 \pm 0.01$ & $0.84 \pm 0.04$ & $3.36 \pm 0.29$ \\
\hline
\end{tabular}

* Strains from the fungal collection of the AFRC Institute of Animal Physiology and Genetics Research, Babraham, Cambridge, UK ; N2 is Neocallimastix patriciarum; $\mathrm{P} 1$ is Piromyces communis; $\mathrm{P} 2$ is Piromyces sp.

$\dagger$ Hydrogen production measured in the head space was normalized to the volume of liquid in the culture bottles.

Table 3. Growth and digestion of cellulose and wheat straw by several anaerobic fungi after cultivation in defined medium M2

Each experimental value represents the mean \pm SD $(n=3)$.

\begin{tabular}{|c|c|c|c|c|c|c|c|c|}
\hline \multirow[b]{2}{*}{ Strain* } & \multicolumn{4}{|c|}{ Wheat straw } & \multicolumn{4}{|c|}{ Filter paper } \\
\hline & $\begin{array}{l}\text { Incubation } \\
\text { time } \\
\text { (h) }\end{array}$ & $\begin{array}{l}\text { Period of } \\
\text { growth } \\
\text { (h) } \dagger\end{array}$ & $\begin{array}{l}\text { Fungal DM } \\
\qquad\left(\mathrm{g}^{-1}\right) \ddagger\end{array}$ & $\begin{array}{l}\text { Digestion } \\
(\%)\end{array}$ & $\begin{array}{l}\text { Incubation } \\
\text { time } \\
\text { (h) }\end{array}$ & $\begin{array}{l}\text { Period of } \\
\text { growth } \\
\text { (h) } \dagger\end{array}$ & $\begin{array}{l}\text { Fungal DM } \\
\qquad\left(\mathrm{g}^{-1}\right) \ddagger\end{array}$ & $\begin{array}{c}\text { Digestion } \\
(\%)\end{array}$ \\
\hline El & 168 & 148 & $0.11 \pm 0.01$ & $41 \pm 2$ & 164 & 145 & $0.05 \pm 0.02$ & $17 \pm 2$ \\
\hline E2 & 144 & 105 & $0.23 \pm 0.02$ & $68 \pm 0$ & 90 & 60 & $0.23 \pm 0.01$ & $96 \pm 1$ \\
\hline E3 & 92 & 78 & $0.20 \pm 0.03$ & $60 \pm 1$ & 92 & 60 & $0.20 \pm 0.02$ & $97 \pm 0$ \\
\hline M1 & 95 & 54 & $0.22 \pm 0.02$ & $52 \pm 3$ & 90 & 60 & $0.33 \pm 0.01$ & $90 \pm 2$ \\
\hline $\mathrm{Nl}$ & 95 & 78 & $0.36 \pm 0.06$ & $68 \pm 2$ & 95 & 60 & $0.50 \pm 0.05$ & $97 \pm 1$ \\
\hline $\mathrm{N} 2$ & 92 & 78 & $0.45 \pm 0.09$ & $64 \pm 3$ & 164 & 65 & $0.50 \pm 0.09$ & $95 \pm 1$ \\
\hline P1 & 120 & 114 & $0.27 \pm 0.03$ & $61 \pm 1$ & 120 & 90 & $0.43 \pm 0.03$ & $96 \pm 1$ \\
\hline P2 & 144 & 115 & $0.09 \pm 0.05$ & $30 \pm 3$ & 144 & 136 & $0.17 \pm 0.05$ & $38 \pm 1$ \\
\hline R1 & 95 & 78 & $0.22 \pm 0.02$ & $65 \pm 1$ & 94 & 60 & $0.33 \pm 0.02$ & $94 \pm 1$ \\
\hline R2 & 144 & 140 & $0.18 \pm 0.01$ & $62 \pm 1$ & 240 & 150 & $0.43 \pm 0.05$ & $88 \pm 4$ \\
\hline R3 & 168 & 130 & $0 \cdot 16 \pm 0.01$ & $60 \pm 1$ & 168 & 120 & $0 \cdot 16 \pm 0.03$ & $53 \pm 4$ \\
\hline R4 & 168 & 135 & $0.15 \pm 0.03$ & $53 \pm 4$ & 168 & 122 & $0.21 \pm 0.02$ & $61 \pm 5$ \\
\hline
\end{tabular}

* Strains are listed in Table 1 and in the first footnote of Table 2.

$\dagger$ The period of growth was estimated from the $\mathrm{H}_{2}$ production curves.

$\ddagger$ Estimated from lipid phosphate contents of residues.

of Neocallimastix strain $\mathrm{N} 1$ and Piromyces strain R1 remained constant during the period of fast growth and autolysis.

Growth of the anaerobic fungi on wheat straw and filter paper cellulose in defined medium M2

The ability of the different strains to grow on wheat straw and filter paper cellulose was examined. Wheat straw and filter paper cellulose digestion correlated with hydrogen production (data not shown). For each fungus the duration of growth was estimated from hydrogen production curves. Fungal growth and digestion of filter paper cellulose and wheat straw was determined after hydrogen production stopped (Table 3). All values were corrected for DM losses due to non-microbial solubilization during preparation and incubation of the medium. Most strains digested more than $60 \%$ of the wheat straw, 

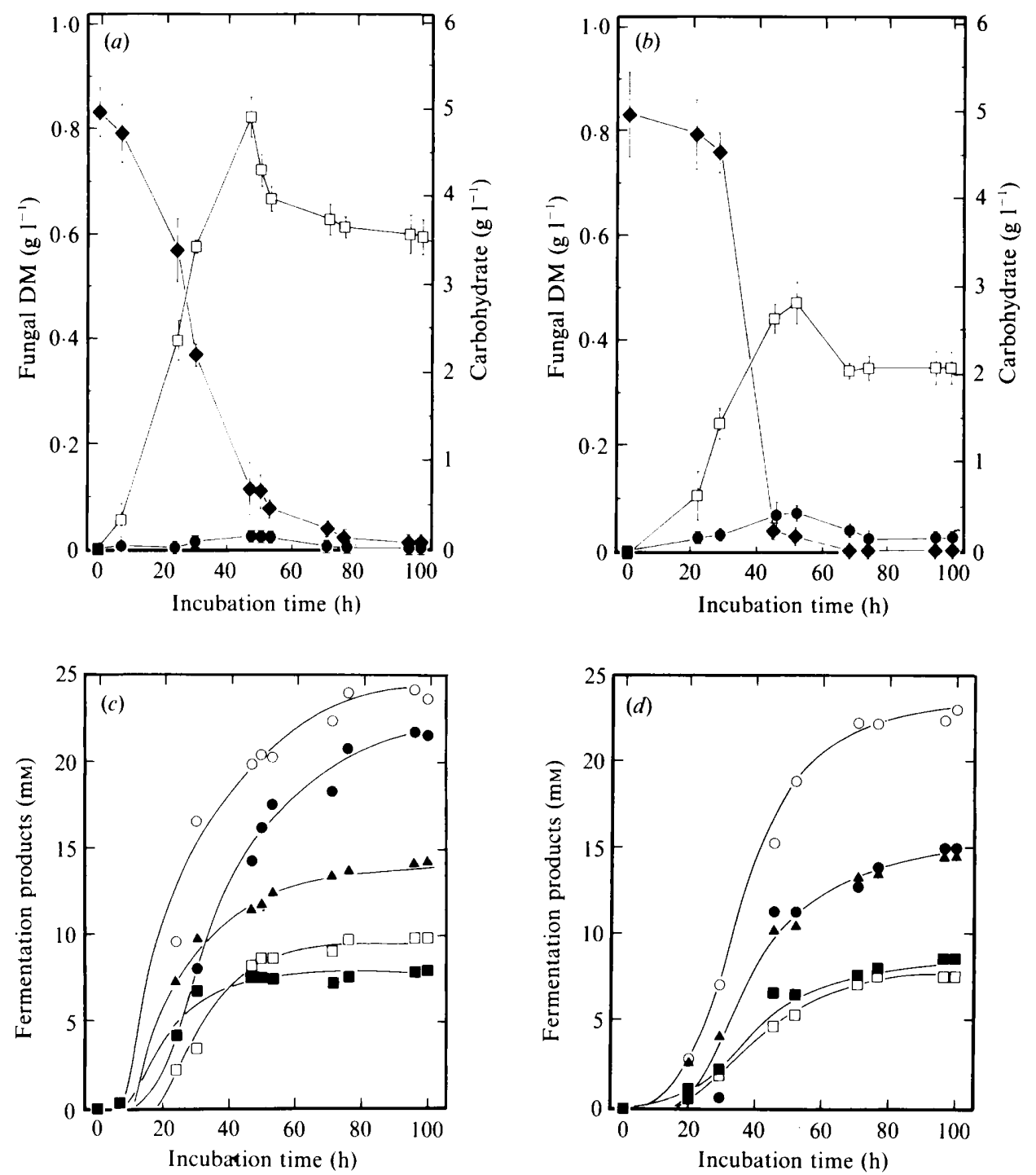

Fig. 1. $(a, b)$ Growth of Neocallimastix strain N1 (a) and Piromyces strain R1 (b) in defined medium M2 containing $0.5 \%(\mathrm{w} / \mathrm{v})$ cellobiose as substrate. $\square$, Fungal dry matter; $\bullet$, cellobiose; - glucose. $(c, d)$ Formation of end-products by strains $\mathrm{N} 1(c)$ and $\mathrm{R} 1(d)$ during growth on cellobiose in defined medium M2. O, Formate;, lactate; $\boldsymbol{\Delta}$, acetate; $\boldsymbol{\square}$, ethanol; $\square$, hydrogen. Hydrogen was measured in the headspace and normalized to the volume of liquid in the culture bottles. Each value represents the mean of three replicates. Bars in $(a)$ and $(b)$ represent the SD. $(n=3)$; in $(c)$ and $(d)$ the standard deviations were all less than $10 \%$ of the mean.

but Piromyces strains E1 and P2 digested only $41 \%$ and $30 \%$, respectively. After a lag period between 6 and $38 \mathrm{~h}$, the period during which growth on wheat straw occurred varied between 54 and $148 \mathrm{~h}$. Strains digesting wheat straw most rapidly were Neocallimastix strains $\mathrm{N} 1$ and N2, and Piromyces strains E2 and R1.

All strains were able to use filter paper as a substrate. The differences between the strains that were observed during the digestion of wheat straw followed the same pattern with filter paper cellulose, and were even more pronounced. Most strains digested the substrate almost completely, although the period of growth of the different strains varied between 60 and $145 \mathrm{~h}$. As found with wheat straw, Piromyces strains E1 and P2 digested less filter paper cellulose than the other isolates. The strains digesting more then $90 \%$ of the cellulose within a growth period of approximately $60 \mathrm{~h}$ were Neocallimastix strain N1 and Piromyces strains E2, E3 and R1.

\section{Growth on cellobiose in defined medium M2}

The growth of Neocallimastix strain N1 (isolated from a ruminant) and Piromyces strain Rl (isolated from a nonruminant) was studied in more detail. Growth of the two strains in defined medium M2 with cellobiose as substrate was followed during a time-course study (Fig. $1 a, b)$. 
After a lag period of $8 \mathrm{~h}$ Neocallimastix strain N1 started to grow and fungal dry matter increased to a maximum of $0.82 \mathrm{~g}^{-1} 48 \mathrm{~h}$ after inoculation (Fig. $1 a$ ). During this period $91 \%$ of the cellobiose was used and the growth yield was $64 \cdot 1 \mathrm{~g}$ (mol substrate) $)^{-1}$. During the period of fast growth $(8-48 \mathrm{~h})$ a small amount of glucose $\left(0 \cdot 16 \mathrm{~g} \mathrm{l}^{-1}\right)$ temporarily accumulated. After exhaustion of the substrate the fungal DM decreased rapidly to approximately $70 \%$ of the maximal value at $76 \mathrm{~h}$. From this time on the fungal DM remained stable.

After a short initial lag period, the fungal dry weight of Piromyces strain R1 increased rapidly between 21 and $52 \mathrm{~h}$ and reached a maximum of $0.49 \mathrm{~g} \mathrm{l}^{-1}$ at $52 \mathrm{~h}$ (Fig. $1 b$ ). During this period of fast growth $98 \%$ of the cellobiose was used and the growth yield was $34.2 \mathrm{~g}$ (mol substrate $)^{-1}$. Glucose accumulated transiently in this period to a maximum of $0.43 \mathrm{~g} \mathrm{l}^{-1}$ after $52 \mathrm{~h}$; by $100 \mathrm{~h}$ most of the glucose had been used and only $0.08 \mathrm{~g} \mathrm{t}^{-1}$ could be detected in the medium. By $65 \mathrm{~h}$ after inoculation the cellobiose had been utilized and the fungal DM of strain R1 had fallen to, and thereafter remained at, approximately $70 \%$ of the maximal value.

\section{Fermentation products}

Growth of both fungi on cellobiose resulted in a mixed acid type of fermentation with formate, acetate, lactate, ethanol and hydrogen as end-products (Fig. $1 c, d$ ). No $\mathrm{C}_{3}-\mathrm{C}_{6}$ volatile fatty acids or $\mathrm{C}_{1}-\mathrm{C}_{5}$ alcohols other than ethanol could be detected.

Formic and lactic acid were the major end-products of strain N1, reaching 24.0 and $21.6 \mathrm{mM}$, respectively, $75 \mathrm{~h}$ after inoculation (Fig. 1c). During the same period, acetic acid and ethanol increased to 14.1 and $7.8 \mathrm{~mm}$, respectively. Hydrogen, normalized to the volume of liquid in the culture bottles, increased to $9.7 \mathrm{~mm}$.

The fermentation of cellobiose by Piromyces strain R1 produced formic acid as the major end-product $(22.9 \mathrm{~mm})$ (Fig. $1 d$ ). Lactic and acetic acids were formed in equimolar amounts, reaching 14.9 and $14.4 \mathrm{~mm}$, respectively, $76 \mathrm{~h}$ after inoculation. During the period of growth ethanol increased to $8.6 \mathrm{~mm}$ and hydrogen to $7.5 \mathrm{~mm}$.

\section{Comparison of growth in complex medium MI and defined medium M2 with cellobiose as substrate}

The omission of the complex compounds and the more diluted vitamin solution had no effect on the growth yield of either Neocallimastix strain N1 or Piromyces strain R1. The fermentation pattern was slightly influenced by the omission of the complex compounds. In medium M1 Neocallimastix strain N1 produced $90 \%$ more ethanol, $30 \%$ more hydrogen and $15 \%$ less formate whereas
Piromyces strain R1 grown in medium M1 produced $200 \%$ more ethanol, $20 \%$ more hydrogen and $15 \%$ less formate than when grown in medium M2. Acetate and lactate production was the same in both media.

\section{Discussion}

This study describes the isolation of anaerobic fungi from several herbivores, ruminant as well as nonruminant. Failure to isolate anaerobic fungi from four of the ten surveyed animal species may have been because the faeces were too old rather than because these animals lacked anaerobic fungi. Milne et al. (1989) showed that no fungi could be isolated from sheep faecal pellets after storage for $1 \mathrm{~d}$ under the conditions used in this study. All of the anaerobic fungi isolated from non-ruminants were Piromyces-like organisms, i.e. the vegetative stage consisted of a monocentric sporangium with branched rhizoid; the released zoospores possessed not more than four flagella (Kudo et al., 1990). The isolation of a fungal species of the genus Caecomyces from a non-ruminant (horse) has been reported previously (Gold $e t$ al., 1988). The fungus we isolated from the rumen of a sheep was of the Neocallimastix type: it formed monocentric sporangia and an extensive network of branched rhizoids; the zoospores possessed numerous flagella (Heath et al., 1983; Orpin \& Munn, 1986). All Neocallimastix species so far described have been isolated from ruminants: from sheep (Orpin, 1975; Heath et al., 1983; Lowe et al., 1985; Phillips \& Gordon, 1989), cattle (Orpin, 1988), reindeer, camel and antelope (Orpin \& Joblin, 1988; Milne et al., 1989).

Defined media have great advantages over complex media. For cultivation of anaerobic fungi, complex media containing rumen fluid, yeast extract, protein digests, etc., have been described (Bauchop, 1979; Kemp et al., 1984; Phillips \& Gordon, 1989), but until now only two defined media have been described (Lowe et al., 1985; Orpin \& Greenwood, 1986). Many of the new isolates grew slowly in the medium of Lowe et al. (1985) and several isolates did not grow in the medium of Orpin \& Greenwood (1986) (data not shown). The major advantage of defined medium M2 was that it ensured good growth of all the new isolates. However, a Piromyces species (P3) and Caecomyces communis (S1) from the AFRC collection failed to grow. These strains have been cultivated for a long time in a complex medium (Kemp et al., 1984) and may have become dependent on complex nutrient factors. Haemin was necessary for optimal growth of the anaerobic fungi, as was found for Neocallimastix patriciarum by Orpin \& Greenwood (1986). Compared to the defined medium of Lowe et al. (1985), defined medium M2 contains no 
volatile fatty acids, a 25 - to 40 -fold lower concentration of vitamins, and a buffer composition which is normally used for the cultivation of rumen micro-organisms. Defined medium M2 differs from the defined medium of Orpin \& Greenwood (1986) in that trace elements and more vitamins were added.

Several methods can be used to determine growth of micro-organisms on solid substrates. Hydrogen and formate production can be used to determine anaerobic fungal growth (Pearce \& Bauchop, 1985; Lowe et al., $1987 a$ ); however comparative growth yield measurements cannot be made as the formation of these endproducts is substrate dependent. The lipid phosphate content of micro-organisms has been used to determine the mass of micro-organisms during growth on solid substrates or in natural environments (White et al., 1979). The lipid phosphate content of the anaerobic fungi studied here varied between 1.97 and $3.36 \mathrm{mg}$ phosphate per g DM. Comparison with literature values is hampered because it is unclear if values are expressed on basis of lipid phosphorus or lipid phosphate (Kemp et al., 1984; Orpin \& Greenwood, 1986). Direct biomass estimations of fungi grown with wheat straw as a substrate are always influenced by residual substrate. Values for wheat straw and cellulose digestion were adjusted on the assumption that the lipid phosphate contents of fungi grown on soluble and insoluble substrates are the same.

The degradation of cellulose and wheat straw by rumen anaerobic fungi has been reported before (Bauchop, 1979; Pearce \& Bauchop, 1985; Lowe et al., 1987b; Gordon \& Phillips, 1989). Anaerobic fungi were isolated on cellulose and wheat straw by Milne et al. (1989), but digestion of these substrates was not quantified. All the anaerobic fungi tested in this study, isolated from both ruminants and non-ruminants, were able to use cellulose and wheat straw. The strains with the highest capacity for cellulose and wheat straw digestion were isolated from sheep, Indian elephant, and black rhinoceros. Only two of the tested strains showed low cellulose and wheat straw digestion. This study demonstrated that anaerobic fungi from ruminants and non-ruminants have similar abilities to degrade cellulose and wheat straw.

Although $\leq 97 \%$ of cellulose was digested by the anaerobic fungi only $\leq 68 \%$ of wheat straw was digested. This is probably due to the high lignin content of the wheat straw used $(11 \%)$. The maximum wheat straw digestion of $68 \%$ observed is considerably higher than the $43-45 \%$ DM loss previously reported for Neocallimastix species (Gordon \& Phillips, 1989; Lowe et al., $1987 b$ ). The low substrate loading used in this study $(0.05 \%, \mathrm{w} / \mathrm{v})$ compared to that $(0.1 \%)$ in both other studies may account for this. Furthermore, wheat straw degradation is likely to be higher than the reported loss of
DM due to formation of fungal DM, but this cannot account completely for the difference. Strains with low cellulolytic capacity also had a low wheat straw digestion capacity. However, the digestion of wheat straw by these strains was higher than the digestion of filter paper cellulose; this may indicate that wheat straw hemicellulose is more easily degraded than cellulose.

Growth yields of the two fungi studied in detail were equal in medium $M 1$ and medium $M 2$, suggesting that the Bactocasitone, yeast extract and rumen fluid contain no compounds which contribute to growth yields. Piromyces strain $\mathrm{R} 1$ is the first anaerobic fungus isolated from a non-ruminant whose fermentation pattern has been described. Its major fermentation products were similar to those formed by Neocallimastix strain N1 and other rumen anaerobic fungi grown on carbohydrates (Orpin \& Munn, 1986; Lowe et al., 1987a).

The growth of Neocallimastix strain N1 and Piromyces strain $\mathbf{R} 1$ on cellobiose in medium M2 showed a pattern which was typical for anaerobic rumen fungi (Lowe $e t$ al., 1987a ; Phillips \& Gordon, 1989). The growth of both fungi appeared to be linear during the entire growth phase. For most fungi, initial growth is exponential and usually followed by a longer period of declining growth rate which can appear as linear growth (Griffen, 1981). To answer the question if this is also the case for the isolates examined here, more frequent sampling and synchronization of growth are required. The autolysis of the fungi after substrate exhaustion that we observed was also found for other anaerobic fungi (Lowe et al., 1987a; Phillips \& Gordon, 1989).

Although the growth yield of Neocallimastix strain N1 was double that of Piromyces strain R1, the accumulation of fermentation products was nearly identical. Although succinate and malate could only be detected in trace amounts for both strains (data not shown), unidentified end-products or the accumulation of storage carbohydrates, as was shown to occur during growth on cellobiose (Phillips \& Gordon, 1989), may have caused the observed difference in growth yield. The lower growth yield of strain $\mathrm{R} 1$ is comparable to the yields reported for Neocallimastix and Piromyces species (Phillips \& Gordon, 1989).

During the fast growth of the two tested anaerobic fungi on cellobiose small amounts of glucose were found to accumulate transiently, presumably because the rate of sugar release by extracellular enzyme action was greater than the rate of utilization for growth. $\beta$ Glucosidase activity has been found in the medium during cultivation of anaerobic fungi on several substrates including cellulose, cellobiose, glucose and wheat straw (Pearce \& Bauchop, 1985; Gordon \& Phillips, 1989; Lowe et al., 1987 b). It is not known if all cellobiose is hydrolysed extracellularly or partly hydrolysed extra- 
cellularly and partly transported across the membrane and hydrolysed intracellularly.

The contribution of anaerobic fungi to forage fibre digestion in vivo is not yet clear. Orpin \& Bountiff (1978), supported by Bauchop (1979), suggest that anaerobic fungi are the initial colonizers of forage fibre in the rumen. In vivo anaerobic rumen fungi may represent up to $8 \%$ of the microbial biomass (Orpin, 1983/1984). Since they are very active in the digestion of a wide range of cell wall polymers (Lowe et al., $1987 b$; Williams \& Orpin, 1987 ) it is likely that they have a significant role in the rumen. This study has demonstrated that pure cultures of anaerobic fungi from foregut-fermenting and, in particular, hindgut-fermenting herbivores, are fibrolytic and able to degrade cellulose and wheat straw in vitro. The fungal biomass in non-ruminants in vivo and its contribution to forage fibre digestion in the animal remain to be studied.

This research was supported by grants from the Technology Foundation (STW) and the Ministry of Economic Affairs of The Netherlands.

\section{References}

BARR, D. J. S. (1988). How modern systematics relate to the rumen fungi. BioSystems 21, 351-356.

Barr, D. J. S., Kudo, H., JAKober, K. \& Cheng, K.-J. (1989) Morphology and development of rumen fungi: Neocallimastix sp., Piromyces communis, and Orpinomyces bovis gen. nov., sp. nov. Canadian Journal of Botany 67, 2815-2824.

BAUCHOP, T. (1979). The rumen anaerobic fungi: colonizers of plant fiber. Annales de Recherches Vétérinaires 10, 246-248.

BergmeYer, H. U. \& BERNT, E. (1974). D-Glucose. Bestimmung mit Glucose-Oxydase und Peroxydase. In Methoden der Enzymatischen Analyse, band 2, pp. 1250-1257. Edited by H. U. Bergmeyer \& K. Gawehn. Weinheim: Verlag Chemie.

Breton, A., Bernalier, A., Bonnemoy, F., Fonty, G., Gaillard, B. \& GOUET, P. (1989). Morphological and metabolic characterization of a new species of strictly anaerobic rumen fungus: Neocallimastix joyonii. FEMS Microbiology Letters 58, 309-314.

Goering, H. K. \& Van Soest, P. J. (1970). Forage Fiber Analyses. Apparatus, reagents, procedures and some applications. Agricultural Research Service Agricultural Handbook no. 379. Washington, DC: US Department of Agriculture.

Gold, J. J., HeATH, I. B. \& BAUChOP, T. (1988). Ultrastructural description of a new chytrid genus of caecum anaerobe, Caecomyces equi gen. nov., sp. nov., assigned to the Neocallimasticaceae. BioSystems 21, 403-415.

Gordon, G. L. R. \& Phillips, M. W. (1989). Degradation and utilization of cellulose and straw by three different anaerobic fungi from the ovine rumen. Applied and Environmental Microbiology 55, 1703-1710.

Griffen, D. H. (1981). Fungal Physiology. New York: John Wiley.

Heath, I. B., Bauchop, T. \& Skipp, R. A. (1983). Assignment of the rumen anaerobe Neocallimastix frontalis to the Spizellomycetales (Chytridiomycetes) on the basis of its polyflagellate zoospore ultrastructure. Canadian Journal of Botany 61, 295-307.

Kemp, P., Lander, D. J. \& OrPin, C. G. (1984). The lipids of the rumen fungus Piromonas communis. Journal of General Microbiology 130, 27-37.
Kudo, H., Jacober, K. D., Phillipe, R. C., Cheng, K.-J., Barr, D. J. S. \& COSTERTON, J. W. (1990). Isolation and characterization of cellulolytic anaerobic fungi and associated mycoplasmas from the rumen of a steer fed a roughage diet. Canadian Journal of Microbiology 36, 513-517.

Lowe, S. E., Theodorou, M. K., Trinci, A. P. J. \& Hespell, R. B. (1985). Growth of anaerobic rumen fungi on defined and semidefined media lacking rumen fluid. Journal of General Microbiology 131, 2225-2229.

Lowe, S. E., Theodorou, M. K. \& Trinci, A. P. J. (1987a). Growth and fermentation of an anaerobic rumen fungus on various carbon sources and effect of temperature on development. Applied and Environmental Microbiology 53, 1210-1215.

Lowe, S. E., Theodorou, M. K. \& Trinci, A. P. J. (1987b). Cellulases and xylanase of an anaerobic rumen fungus grown on wheat straw holocellulose, cellulose, and xylan. Applied and Environmental Microbiology 53, 1216-1223.

Milne, A., Theodorou, M. K., Jordan, M. G. C., King-SPOONer, C \& TRINCI, A. P. J. (1989). Survival of anaerobic fungi in feces, in saliva, and in pure culture. Experimental Mycology 13, 27-37.

OrPIN, C. G. (1975). Studies on the rumen flagellate Neocallimastix frontalis. Journal of General Microbiology 91, 249-262.

ORPIN, C. G. (1976). Studies on the rumen flagellate Sphaeromonas communis. Journal of General Microbiology 94, 270-280.

OrPIN, C. G. (1977). The rumen flagellate Piromonas communis: its lifehistory and invasion of plant material in the rumen. Journal of General Microbiology 99, 107-117.

ORPIN, C. G. (1981). Isolation of cellulolytic phycomycete fungi from the caecum of the horse. Journal of General Microbiology 123, 287296.

OrPIN, C. G. (1983/1984). The role of ciliate protozoa and fungi in the rumen digestion of plant cell walls. Animal Feed Science Technology 10, 121-143.

ORPIN, C. G. (1988). Nutrition and biochemistry of anaerobic Chytridiomycetes. BioSystems 21, 365-370.

ORPIN, C. G. \& BountIFF, L. (1978). Zoospore chemotaxis in the rumen phycomycete Neocallimastix frontalis. Journal of General Microbiology 104, 113-122.

ORPIN, C. G. \& GREeNwOOD, Y. (1986). Nutritional and germination requirements of the rumen chytridiomycete Neocallimastix patriciarum. Transactions of the British Mycological Society 86, 103-109.

ORPIN, C. G. \& Joblin, K. N. (1988). The rumen anaerobic fungi. In The Rumen Microbial Ecosystem, pp. 129-151. Edited by P. N. Hobson. London: Elsevier Applied Science.

ORPIN, C. G. \& MUNN, E. A. (1986). Neocallimastix patriciarum sp. nov., a new member of the Neocallimasticaceae inhabiting the rumen. Transactions of the British Mycological Society 86, 178-181.

PEARCE, P. D. \& BAUChOP, T. (1985). Glycosidases of the rumen anaerobic fungus Neocallimastix frontalis grown on cellulosic substrates. Applied and Environmental Microbiology 49, 1265-1269.

PhILlips, M. W. \& GoRdon, G. L. R. (1989). Growth characteristics on cellobiose of three different anaerobic fungi isolated from the ovine rumen. Applied and Environmental Microbiology 55, 1695-1702.

Russell, J. B. \& BALDWIN, R. L. (1978). Substrate preferences in rumen bacteria: evidence of catabolite regulatory mechanisms. Applied and Environmental Microbiology 36, 319-329.

Sleat, R. \& MAH, R. A. (1984). Quantitative method for colorimetric determination of formate in fermentation media. Applied and Environmental Microbiology 47, 884-885.

Teunissen, M. J., Marras, S. A. E., Op den Camp, H. J. M. \& Vogels, G. D. (1989). An improved method for the quantification of alcohols, volatile fatty acids, and lactate or 2,3-butanediol in biological samples. Journal of Microbiological Methods 10, 247-254.

White, D. C., Davis, W. M., Nickels, J. S., King, J. D. \& Bobbie, R. J. (1979). Determination of the sedimentary biomass by extractible lipid phosphate. Oecologia 40, 51-62.

Williams, A. G. \& ORPIN, C. G. (1987). Polysaccharide-degrading enzymes formed by three anaerobic rumen fungi grown on a range of carbohydrate substrates. Canadian Journal of Microbiology 33, 418426. 